\title{
Removal of Algae by Sonicator: A case study from Per Aru Reservoir
}

\author{
T. Thurkka1, N. Anoja ${ }^{2}$, T. Mikunthan ${ }^{1}$ and A.C.Thavaranjit ${ }^{3}$ \\ ${ }^{I}$ Dept. of Agric. Engineering, Faculty of Agriculture, University of Jaffna \\ ${ }^{2}$ National Water Supply and Drainage Board, Vavuniya. \\ ${ }^{3}$ Dept. of Botany, Faculty of Science, University of Jaffna
}

\begin{abstract}
Per Aru is a reservoir which rises in Vavuniya district, Northern Province, Sri Lanka with the length and basin size of $32 \mathrm{Km}$ and $372 \mathrm{Km}^{2}$ respectively. Per Aru reservoir is for the sole purpose of supplying drinking water to the urban area of Vavuniya district by National Water Supply and Drainage Board. Major problem was identified as very high algal population in the Per Aru reservoir. Hence research was focused on efficiency of ultrasound wave's technology (Quattro- DB sonicator) to reduce the algal population in Per Aru reservoir and to evaluate the change of colour and turbidity for drinking water supply. Raw water samples were collected from April to July 2018 at monthly interval from different distance from sonicator; $50 \mathrm{~m}, 100 \mathrm{~m}, 150 \mathrm{~m}, 200 \mathrm{~m}$ and $500 \mathrm{~m}$ as control in three different depths as surface, middle and bottom. EC, pH, turbidity, total hardness, nitrate, phosphate and total iron were tested. Algae population also was countered. All the parameters were within the recommended level of Sri Lankan drinking water standards except colour and turbidity. The colour (20 - 75 Pt-Co) and Turbidity (3.03 - 5.97 NTU) was very high. Efficiency of sonicator was high in the surface and algal removal percentage was ranges from 76 to $85 \%$. Ultrasonic algal control has favourable results and sonicator efficiency was reduced with increasing distance and was reduced with increasing depth from surface to bottom. Statistical analysis shows that there were no significant variation in the efficiency in $50 \mathrm{~m}$ and $100 \mathrm{~m}$ distance. Algae were significantly removed in $50 \mathrm{~m}, 100 \mathrm{~m}$ than the $200 \mathrm{~m}$ distance from the sonicator. Finally it was concluded that Per Aru reservoir has colour, turbidity and algae problem and conventional treatment is important to remove colour and turbidity. Ultrasonication has effectively control the algal population in Per Aru reservoir.
\end{abstract}

Key words: Algae, Colour, Per Aru reservoir, Quattro-DB sonicator, Turbidity.

\section{INTRODUCTION}

Ultrasound is sound waves with frequencies higher than the upper audible limit of human hearing $(22 \mathrm{kHz})$. At specific frequencies, these sound waves can be used to control algae growth (Cum et al., 1992; Zhang et al., 2006). Cyanobacteria use gas vesicles for buoyance and depth regulation. During the day time algae are photosynthesizing in the top layer, using carbondioxide and dissolved nutrients from the surrounding water to produce oxygen and polysaccharides. At night, the cyanobacteria cells empty their gas vesicles (vacuole) to sink to the bottom and use oxygen and nutrients to produce biomass (Hongwei Hao et al., 2004). Ultrasound waves create a sound layer in the top layer of the water. The sound layer has a direct impact on the buoyancy of the algae. The algae cells will sink to the bottom and are unable to photosynthesize and eventually die due to a lack of light (Jiang et al., 2012). Ultra-sonic can destroy the algae by initially physical pathways that the main destroying performed by cavitation phenomena (Lee et al., 2001).

Presence of Algae population is the major 
water quality issue in drinking water supply reservoirs. Algae massively reproduce under sufficient nitrogen and phosphorus (Jiang et al., 2012). Algae population causes serious problems. Sunlight cannot transmit through water body which is covered by algae. Algae use almost all dissolved oxygen. Hence aquatic organisms die due to oxygen deficient. Thus ecological equilibrium of water body is destroyed by algal bloom (Jiang et al., 2012). Algae population not only increase water turbidity but also the source of undesirable taste and odour concerns (Hitzfeld et al., 2000). Fresh water algal blooms have the ability to produce toxins which is dangerous to organisms such as dogs, and livestock including humans. Most of the blue-green algae are toxin produce algae. Most harmful algal bloom occurs in warm, slow moving, eutrophic waters. In tap water production, algae can block filter tank, increase back wash water quantity, penetrate filter tank, and deteriorate water turbidity and quality (Jiang et al., 2012).

A number of approaches are available to control algae blooms in water bodies including minimizing nutrient loading, addition of algaecides, aeration, and artificial mixing the use of filters embedded with activated carbon (Lijun Xiang et al., 2005). Minimizing nutrient loading is not generally practiced as it is very difficult to get support from the agricultural communities. An excessive use of algaecides can itself lead to additional problems of pollution in water bodies. Although aeration, artificial mixing, filter embedded with activated carbon can control algae blooms but cannot easily be applied on a large scale to reservoirs (Eadaoin et al., 2010). A more recent approach to control algae is the use of ultrasound. There are no additives introduced into the ultra-sonic system and no byproducts generated by ultrasonic technology.
Therefore, there are no anticipated environmental concerns associated with this technology. But when suspended solids of effluent increase, it may increase the turbidity or suspended solids

Per Aru is a reservoir which rises in Vavuniya district, Northern Province, Sri Lanka. Per Aru reservoir is for the sole purpose of supplying drinking water to the urban area of Vavuniya district by National water supply and drainage board (NWSDB). The capacity of the Per Aru reservoir is $6000 \mathrm{~m}^{3} /$ day. But at present, the plant is running with $3000 \mathrm{~m}^{3} /$ day and extension of water supply points are in progress to other areas. Algae bloom is main problem in Per Aru reservoir. Removal of algae is needed for supplying drinking water to the urban area in Vavuniya district.

Hence study was conducted to estimate the effectiveness of algal removal by Quattro DB Sonicator in Per Aru reservoir, Vavuniya district without changing its frequencies during the period of April to July, 2018.

\section{MATERIALS AND METHODS}

\section{Study area}

Per Aru reservoir is a largest fresh water source in Vavuniya District, Northern Province, Sri Lanka, with the length and basin size of $32 \mathrm{Km}$ and $372 \mathrm{Km}^{2}$ respectively and it has severely affected by high algal population.

Quattro-DB sonicator is working in the central part of the reservoir where submersible pumps are fixed to withdraw the water and operated with lower frequencies bandwidth $(24-58 \mathrm{kHz})$. The depth of water in pump installation point was $4 \mathrm{~m}$ and average depth of water in the reservoir was $3 \mathrm{~m}$. According to the drinking water quality standards, the population of the algae should be zero in treated water. 


\section{Collection and analysis of the water samples}

Water samples were collected from four different locations from the sonicator as 50 $\mathrm{m}, 100 \mathrm{~m}, 150 \mathrm{~m}$ and $200 \mathrm{~m}$ and in three different levels: top, middle and bottom by using custom made piston type sampler from April to July, 2018 at monthly interval. Duplicate sampling was done by selecting two locations from each sampling point. Control samples were collected in $500 \mathrm{~m}$ from the sonicator from three different levels where there was no effect by sonicator. Two sets of samples were collected at each point for algal and physical and chemical testing separately.

\section{Counting the algal population}

Water sample was shaken to ensure a uniform suspension of algal cells. A loopful sample was eluted in between the coverslip and the platform of the Haemacytometer. It was observed under the high power of the light microscope and counted the number of algal units in different square fields. This was repeated 5 times and the average number of algal population / $\mathrm{ml}$ was calculated. Algal removal efficiency of sonicator was calculated by comparing the algal population in control length and algal population in treatment length by assuming similar population density in the reservoir.

\section{Determination of the water quality parameters}

Physical and chemical characters of the water samples were tested. Analytical procedures were based on American
Public Health Association and Sri Lankan standard 614, 2013. EC, pH and turbidity of the water samples were measured using respective digital conductivity meter, $\mathrm{pH}$ meter and turbidity meter respectively. Total Hardness of the samples was tested by EDTA titrimetric method while chloride was tested by silver nitrate titrimetry method. Nitrate, phosphate and total iron were tested using DR 5000 Spectrophotometer.

\section{Statistical analysis}

Statistical analysis was done by using SAS version 9.1.3 and Duncan's multiple range test was done to compare the means.

\section{RESULTS AND DISCUSSION}

\section{Physical and chemical quality of reservoir water}

Variation in physical and chemical characteristics of the reservoir water during the test period in different distance and different depth from sonicator is tabulated in the Table 1. All the parameters were within the recommended range and there were no significant different in monthly values except colour and turbidity. The colour was high in surface water than middle and bottom level water. Colour increases with the increasing distances from sonicator. Colour was low (20-30 Pt/Co unit) in $50 \mathrm{~m}$ from the sonicator and high (60-75 Pt/Co unit) in $200 \mathrm{~m}$ from the sonicator due to different density of alga in different location.. Hence action has to be taken to improve the quality of water by treating for colour and turbidity which is due to algal population. 
Table 1: Variation of physical and chemical quality of Per Aru reservoir

\begin{tabular}{lcc}
\hline Parameters & Unit & Ranges \\
\hline Colour & Pt/Co unit & $20-75$ \\
Turbidity & $\mathrm{NTU}$ & $3.03-5.97$ \\
$\mathrm{pH}$ & - & $8.03-8.48$ \\
$\mathrm{EC}$ & $\mu \mathrm{S} / \mathrm{cm}$ & $621-833$ \\
Chloride & $\mathrm{mg} / \mathrm{L}$ & $111-135$ \\
Nitrate & $\mathrm{mg} / \mathrm{L}$ & $0.7-2.6$ \\
Total Phosphate & $\mathrm{mg} / \mathrm{L}$ & $0.02-0.14$ \\
Total Hardness & $\mathrm{mg} / \mathrm{L}$ & $181-213$ \\
Calcium & $\mathrm{mg} / \mathrm{L}$ & $28-34$ \\
Total Iron & $\mathrm{Mg} / \mathrm{L}$ & $0.03-0.05$ \\
\hline
\end{tabular}

\section{Algal population in control point}

Algae population is higher in surface than the middle and bottom level of water in water resources (Carney et al., 1988). Because sunlight penetration is lower in middle and bottom level of water than surface water. Figure 1shows the algae population in control location (from $500 \mathrm{~m}$ from the sonicator) at different depths (top, middle and bottom level). Algae population is four times higher in surface water than middle and bottom water. The average value of the algal population in the surface water was $12 * 10^{4}$ cell $/ \mathrm{ml}$ of water. It was concluded that high population of algae is present in the surface water of the Per Aru reservoir.

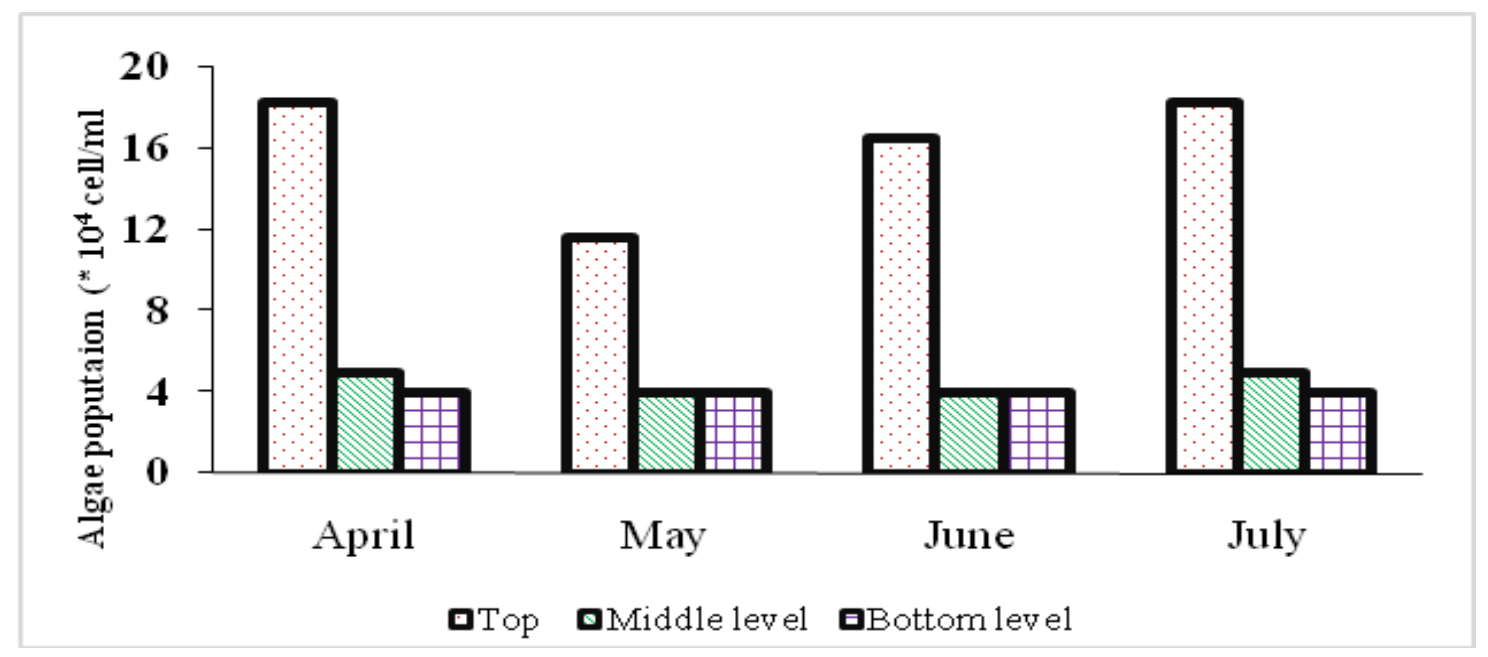

Figure 1: Variation of algal population from April to July in control location

Different types of algal were identified in the Per Aru reservoir (table 2), main types are green algae and blue green algae
(Cyanobacteria) and also different forms were also present as filamentous, unicellular and colonial. 
Table 2: Identified algal types in Per Aru reservoir

\begin{tabular}{ll}
\hline Group & Identified algal types \\
\hline Filamentous blue green algae & Oscillatoria., Nodularia, Anabaena \\
Unicellular blue green algae & Anacystis, Chroococcus \\
Colonial blue green algae & Gloeocapsa, Microcystics \\
Golden brown algae & Pinnate Diatoms \\
Filamentous green algae & Stichococcus, Oedogonium \\
Unicellular green algae & Chlorella \\
\hline
\end{tabular}

\section{Determine the algal removal efficiency of Quattro-DB sonicator}

Figure 2 shows the algal removal percentage in different distance from the sonicator during the month of April to July by comparing algal population in $500 \mathrm{~m}$ distance as control with the assumption of equal population in all the location. Algal removal percentage was reduced with increasing distance in all month except June because collection of water sample was disturbed by high wind during the month of June. Algae were significantly removed in $50 \mathrm{~m}, 100 \mathrm{~m}$ than the $200 \mathrm{~m}$ from the sonicator in all months except June. Efficiency of sonicator reduced with increasing distance with sonicator because of ultra-sonic waves emitting is high in near the distance of sonicator than the longer distance of sonicator.

Statistical analysis shows that there were no significant variations in the efficiency in $50 \mathrm{~m}$ and $100 \mathrm{~m}$ distance in all four months. But there were significant difference in algal removal percentage between $50 \mathrm{~m}$ to $100 \mathrm{~m}$ and $150 \mathrm{~m}$ to 200 $m$ except But there were significant difference in algal removal percentage between $50 \mathrm{~m}$ to $100 \mathrm{~m}$ and $150 \mathrm{~m}$ to 200 $m$ except June (figure 2). Similar studies by Jiang et al., 2009; Eadaoin et al., 2010 confirmed that ultrasound can offer a suitable method for algae inactivation or control but the sonication conditions must be taken into account.

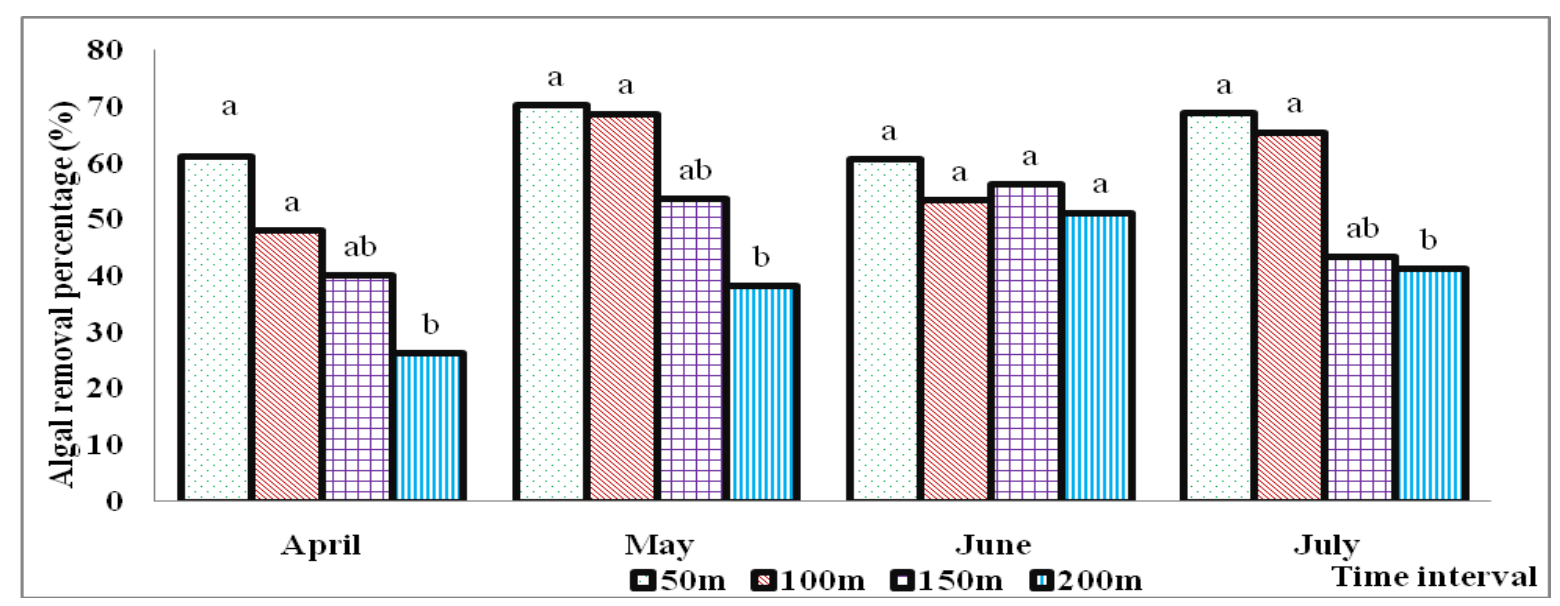

The same letter are not significantly different by DMRT at $p=0.05$

Figure 2: Variation of algal removal percentage from April to July in different distance from sonicator as $50 \mathrm{~m}, 100 \mathrm{~m}, 150 \mathrm{~m}$ and $200 \mathrm{~m}$.

Figure 3 shows the variation of algal removal percentage from April to July in different distance from sonicator with different depth. Efficiency of sonicator was high in the surface water and ranges from 76 to $85 \%$ during the study period. But efficiency of sonicator in middle and bottom level water was lower than $50 \%$. 
Efficiency of sonicator was reduced with increasing depth because of sonicator emits the ultrasonic waves in surface water.

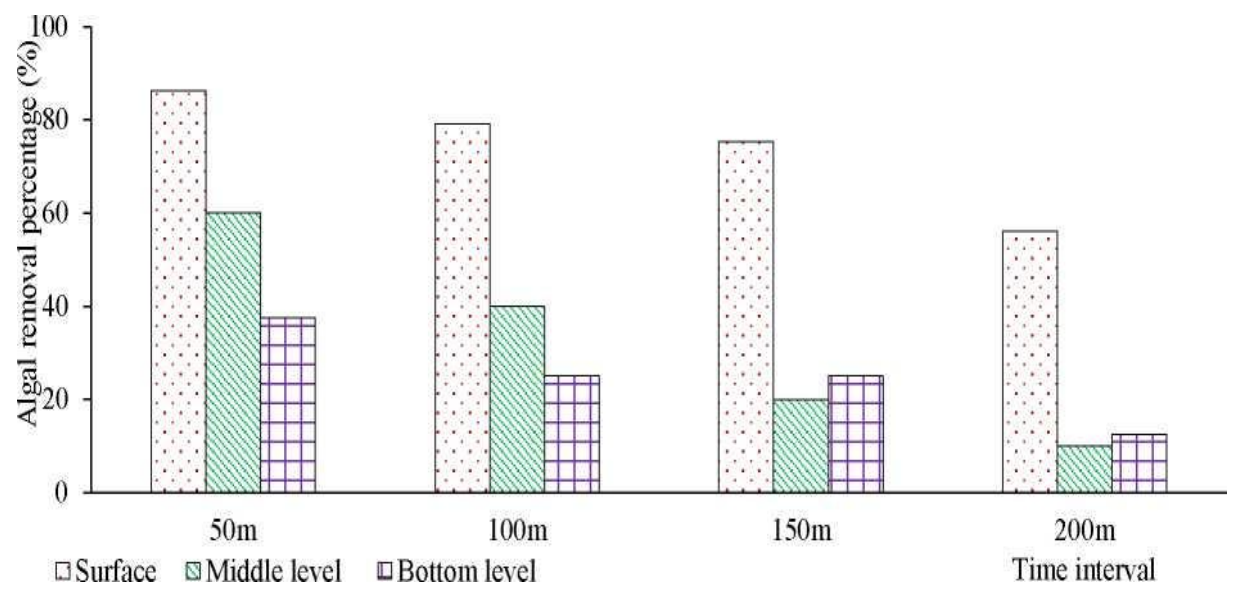

Figure 3: Variation of algal removal percentage from April to July in different distance from sonicator with different depth

\section{Colour}

Colour in drinking water may also be due to the presence of coloured organic matter and algal population (Heng Liang et al., 2009). Drinking water should be colourless. Figure 4 shows the colour of Per Aru reservoir for the period from April to July 2018 and no any significant variation among monthly values and all the values were higher than Sri Lankan drinking water quality standard of 15 $\mathrm{Pt} / \mathrm{Co}$. It could be due to the presence of algae and turbidity. The colour of the water samples was high in surface water than middle and bottom level water in all measurement points because algal population is high in surface water. Colour of water was increased with increasing distance from sonicator because efficiency of sonicator was reduced with increasing distance from sonicator. Since algal population was high in $200 \mathrm{~m}$ from the sonicator than the $50 \mathrm{~m}$ from sonicator, colour also follows the same pattern.



Figure 4: Variation of colour from April to July in different depth and distance from sonicator

\section{Turbidity}

Turbidity is important because it affects the acceptability of water by consumer and the selection and efficiency of treatment processes. Permissible level of drinking water quality standard (SLS 614: 2013) is 2 NTU. Turbidity was increased along the 
distance from the sonicator. There were no significant variation among monthly values and it was higher than Sri Lankan drinking water quality standard of 2NTU. But always top water sample has higher turbidity than bottom sample in all locations. The water samples turbidity range was 3.03 - 5.97 in different distance from sonicator and different depth.

\section{CONCLUSION}

Per Aru reservoir in Vavuniya, is used to supply drinking water to the public. The colour and Turbidity was very high. Hence, conventional treatment is important to remove turbidity and colour. Efficiency of sonicator was high in the surface. Ultrasonic algal control has favourable results and sonicator efficiency was reduced with increasing distance and was reduced with increasing depth from surface to bottom. Algae were significantly removed in $50 \mathrm{~m}, 100 \mathrm{~m}$ than the $200 \mathrm{~m}$ distance from the sonicator. Statistical analysis shows that there were no significant variation in the efficiency in 50 $\mathrm{m}$ and $100 \mathrm{~m}$ distance. But there were significant difference in algal removal percentage between $50 \mathrm{~m}$ to $100 \mathrm{~m}$ and $150 \mathrm{~m}$ to $200 \mathrm{~m}$ except But there were significant difference in algal removal percentage between $50 \mathrm{~m}$ to $100 \mathrm{~m}$ and $150 \mathrm{~m}$ to $200 \mathrm{~m}$ except June Algal removal was successfully done with sonicator.

\section{REFERENCES}

Ambashta, R.D. and Mika Sillanpaa, M. (2010). Water purification using magnetic assistance: A review. Journal of Hazardous Materials, 180: 38-49.

American public Health Association (1965). APHA, AWWA-WPCF, Standard methods for examination of water and waste water, New York (USA), 1965, 6:74-92.

Carney, H.J., Richerson, P.J., Goldman,
C.R. and Richards, R.C. (1988). Seasonal phytoplankton demographic processes and experiments on inerspecific competition. Ecologgy ECOLAR, 69(3): 664 - 678.

Cum, G., Galli, G., Gallo, R. and Spadaro, A. (1992). Role of frequency in the ultrasonic activation of chemical reactions. Ultrasonics, 30(4):267-270.

Eadaoin, J. M., Xiaoge Wu and Timothy, J.M. (2010). Effect of ultrasonic frequency and power on algae suspensions. Journal of Environmental Science and Health, Part A, 45(7): 863-866

Heng Liang, Jun Nan, Wen-jie He and Guibai Li. (2009). Algae removal by ultrasonic irradiation- coagulation. Desalination, 239(1-3):191-197.

Hitzfeld, B.C., Hoger, S.J. and Dietrich, D.R.(2000). Cyanobacterial toxins: removal during drinking water treatment, and human risk assessment. Journal of Hazardous Materials, 180: 38-49

Hongwei Hao, Minsheng $\mathrm{Wu}$, Yifang Chen, Jiaowen Tang and Qingyu Wu. (2004). Cavitation mechanism in cyanobacterial growth inhibition by ultrasonic irradiation. Colloids and Surfaces B: Biointerfaces, 33:151-156.

Jiang, D., Ni, G., Gao, L., Cao, G., Zhang, S. and Bo, G. (2009). Study on Algal Control by Low-Frequency, Low-Power Ultrasonic. Ecology and Environmental Sciences, 18(5):1732-1735.

Jiang, D.L., Guo Wei Ni., Yu Min, Z. and You Po, S. (2012). Algal control by low frequency low power ultrasonic in eutrophic bodies. Advanced materials Research, 433 - 440:811-816.

Lee, T.J., Nakano, K. and Matsumara, M.(2001). Ultrasonic irradiation for bluegreen algae bloom control. Environmental Technology, 22(4):383-390. 
Lijun Xiang, Bochu Wang, Qinghong Wang and Liu Liu. (2005). Kinetics of degradation by immobilized cells with ultrasonic irradiation. Colloids and Surfaces B: Bio interfaces, 45(3-4):162166.

Sri Lanka standard 614 (1983). part 1,
Specification for potable water physical and chemical requirements, unsuitable irrigation water quality, pp: 5-10.

Zhang, G., Zhang, P., Liu, H. and Wang, B. (2006). Ultrasonic damages on cyanobacterial photosynthesis. Ultrasonics Sonochemistry, 13(6):501-505. 